\title{
The effect of radiation exposure and storage time on the degree of conversion and flexural strength of different resin composites
}

\author{
Ragia M. Taher ${ }^{1 *}$ (D, Lamiaa M. Moharam¹, Amin E. Amin², Mohamed H. Zaazou', Farid S. El-Askary ${ }^{3}$ and \\ Mokhtar N. Ibrahim ${ }^{3}$
}

\begin{abstract}
Background: This study was conducted to evaluate the effect of radiation exposure and storage time on the degree of conversion (DC\%) and flexural strength (FS) of three different resin composites. In total, 90 disk-shaped, and 360 rod-shaped composite specimens were prepared to evaluate the DC\% and FS, respectively. Specimens were divided into 18 groups (DC\%: $n=5$ and FS: $n=20$ ) according to the three experimental factors of the study: 1—Radiation (noexposure and exposure), 2-Resin composite material (Herculite XRV Ultra, Z250 XT and Grandio), and 3-Storage time (24 h in distilled water, 3-m and 6-m in 70\% ethanol). Fourier transform infrared spectrometer (FTIR) was used to determine the DC\%. For FS, the specimens were subjected to a three-point bending test at $1 \mathrm{~mm} / \mathrm{min}$ crosshead speed. Data were analyzed using three-way ANOVA/Tukey HSD test. Significant level was set at $P=0.05$.
\end{abstract}

Results: For DC\%, there was no significant difference between no-radiation exposure and radiation exposure $(P>0.05)$. Herculite XRV Ultra revealed the highest statistically significant DC\% $(P<0.05)$. The 24 -h storage time revealed the least significant DC\% $(P<0.05)$. For $F S$, radiation exposure showed a statistically significant higher value compared to no-radiation exposure $(P<0.05)$. Herculite XRV Ultra showed the least FS value $(P<0.05)$. The 24-h storage time showed the highest significant value $(P<0.05)$.

Conclusions: Radiation exposure has no significant impact on the DC\% of the different resin composites, but it has a significant positive effect on the FS. Storage time had a significant effect on both DC\% and FS.

Keywords: Radiation exposure, Resin composite, Storage time, Degree of conversion, Flexural strength

\section{Background}

Radiotherapy is one of the treatments options that are frequently indicated in the treatment of patients with head and neck carcinomas (Nutting 2016). Its adverse effects on the patients' general health and their quality of life are, however, quite significant (Yucel et al. 2014). Secondary effects of radiotherapy on the oral tissues have been studied widely. It is well acknowledged that radiotherapy can cause damage to any normal tissue located

\footnotetext{
*Correspondence: ragia_taher@hotmail.co.uk

${ }^{1}$ Restorative and Dental Materials Department, National Research Centre, Bohouth Street, Dokki, Cairo, Egypt

Full list of author information is available at the end of the article
}

within the radiation field (Barnett et al. 2009). The change in the properties of the different dental restorative materials is one of the adverse effects of the head-and-neck radiotherapy, especially with increasing radiation doses (Brandeburski and Della Bona 2018).

Although resin composites have shown a substantial evolution over the past years, the development of new composites has mainly focused on the increase in the filler's percentage. In general, increasing filler percentage within contemporary resin composites was found to adversely influence the degree of conversion (Rastelli et al. 2012; Halvorson et al. 2009). It was also observed that flexural strength of resin-based composites is greatly 
affected by the filler system characteristics, including filler percentage (Kim et al. 2002; Beun et al. 2007).

In the oral environments, resin composites are exposed intermittently or continuously to chemical agents in saliva, food, and drinks which can cause softening of the resin matrix of the composite resin restorations through water absorption, which causes hydrolytic breakdown of the bond between the filler particles and resin matrix, and eventually de-bonding of the fillers (Ferracane et al. 1998). The medium to which the composite is exposed to, controls the de-bonding mechanism and the resultant loss in material's properties. To simulate the effect of chemicals in the oral environment, several artificial storage procedures such as artificial saliva, acids or ethanol solutions have been used as in vitro storage media (Wu and McKinney 1982).

The properties of resin composites under the different clinical conditions can be evaluated in vitro by the assessment of their mechanical and physical properties. In this regard, the aim of this study was to evaluate the effect of radiation exposure and storage time on the $\mathrm{DC} \%$ and the FS of three different resin composites. The null hypothesis tested was, neither the radiotherapy, nor the storage time has an effect on the DC\% and FS of the three different resin composites.

\section{Methods}

Three different nano-hybrid resin composites were used in this study. Materials, manufactures, composition, and Lot \# are presented in Table 1.

\section{Study design}

In total, 90 resin composite disk-shaped and 360 rodshaped specimens were prepared to evaluate the DC\% and FS, respectively. The specimens were divided into 18 groups ( $n=5 /$ group for DC\% and $n=20 /$ group for FS) according to the three experimental factors of this study: Factor 1: Radiation, 2 groups (no-exposure and radiation exposure), Factor 2: Resin composite, 3 groups (Herculite XRV Ultra, Z250 XT and Grandio), and Factor 3: storage time, 2 groups (24-h in distilled water, $3-\mathrm{m}$, and $6-\mathrm{m}$ in $70 \%$ ethanol).

\section{Preparation of the composite specimens}

For the DC\%, a specially fabricated stainless-steel circular split mold with a central hole measuring $5 \mathrm{~mm}$ diameter $\times 2 \mathrm{~mm}$ thickness was used. The mold was positioned on a glass slide that was covered with a Mylar strip. The investigated resin composite materials were applied inside the mold in a single increment, covered with another Mylar strip, and the resin composites were pressed using glass slide to extrude the excess material and obtain a flat smooth surface. The materials were light-cured for $20 \mathrm{~s}$ according to manufacturer's instructions using LED light curing device, with an output of $1200 \mathrm{~mW} / \mathrm{cm}^{2}$ (Elipar ${ }^{\mathrm{TM}}$ DeepCure-L Light Cure, $3 \mathrm{M}$ ESPE, St. Paul, USA.). The intensity of the LED unit was periodically checked every 10 specimens using a handheld radiometer (CM300-2000, APOZA, Taiwan). A 1200-grit SiC paper was used to remove any flashes from the prepared composite specimens.

Table 1 Materials, manufactures, composition/filler weight \%, and Lot \#

\begin{tabular}{|c|c|c|c|}
\hline Materials & Manufacturer & Composition & Lot \# \\
\hline $\begin{array}{l}\text { Herculite }^{\mathrm{TM}} \\
\text { XRV Ultra }\end{array}$ & $\begin{array}{l}\text { Kerr Italia S.r.l } \\
\text { Via Passanti, } \\
\text { Scafati (SA), Italy }\end{array}$ & $\begin{array}{l}\text { Filler percentage: } 78 \text { wt\% } \\
\text { Pre-polymerized filler (PPF), } \\
\text { Silica nanofillers ( } 20-50 \mathrm{~nm}), \\
\text { Barium glass ( } 0.4 \text { micron), } \\
\text { Methacrylic monomers, } \\
\text { Trimethylolpropane Triacrylate, } \\
\text { TiO, benzoyl peroxide, } \\
\text { 4-Methoxyphenol, initiators, pigments }\end{array}$ & 5679825 \\
\hline $\begin{array}{l}\text { Filtek }^{\mathrm{TM}} \\
\text { Z250 XT }\end{array}$ & $\begin{array}{l}3 \text { M ESPE, } \\
\text { St. Paul, } \\
\text { MN, USA }\end{array}$ & $\begin{array}{l}\text { Filler percentage: } 82 \text { wt } \% \\
\text { Surface modified zirconia/silica } \\
3 \mu \mathrm{m} \text {, non-Agglomerated surface } \\
\text { modified silica } 20 \mathrm{~nm} \text {. BIS-GMA, } \\
\text { UDMA, BIS-EMA, } \\
\text { PEGDMA and TEGDMA }\end{array}$ & N728054 \\
\hline Grandio & $\begin{array}{l}\text { Voco, Guxhaven, } \\
\text { GMBH- } \\
\text { Germany }\end{array}$ & $\begin{array}{l}\text { Filler percentage: } 87 \text { wt\% } \\
\text { Ba-Al-Borosilicate glass filler } \\
\text { (microfiller) } 1 \mu \mathrm{m} \text {, } \\
\mathrm{SiO} 2 \text { (nanofiller) } 20-60 \mathrm{~nm} \\
\text { B-GMA, UDMA and TEGDMA }\end{array}$ & N1511068 \\
\hline
\end{tabular}


For the FS, a specially fabricated rectangular stainlesssteel split mold with a central rectangular window measuring $12 \mathrm{~mm}$ length $\times 2 \mathrm{~mm}$ width $\times 2 \mathrm{~mm}$ thickness was used. The mold was positioned on a glass slide that was covered with a Mylar strip. Resin composite materials were applied, covered with another Mylar strip, and the resin composite was pressed using a glass slide to extrude the excess material and obtain a flat smooth surface. Each specimen was light-cured for $20 \mathrm{~s}$ according to the manufacturer's instructions using the LED curing device. To ensure proper polymerization for each specimen, two overlapping light curing cycles was used, each cycle for $20 \mathrm{~s}$ for a total curing time of $40 \mathrm{~s}$. The top surface of each specimen was marked using a permanent marker before removing from the mold. The dimensions (width $\times$ thickness $\times$ length) of each specimen were measured using a digital caliper (Absolute AOS Digimatic, Mitutoyo, Tokyo, Japan) with an accuracy of $0.01 \mathrm{~mm}$ at three different locations along the length of the specimen. The values of the three measurements were averaged for each specimen to be used in the FS determining equation.

\section{Storage of the composite disks}

The specimens were randomly assigned to the three storage times ( $24 \mathrm{~h}$ in distilled water, $3-\mathrm{m}$ and $6-\mathrm{m}$ in $70 \%$ ethanol solution). Specimens were stored in light-proof container in an incubator at $37^{\circ} \mathrm{C}$ (TITANOX, Via Canove, Italy). For specimens stored in $70 \%$ ethanol, the ethanol solution was replaced every 1 week to avoid saturation by degradation products and partial evaporation of the ethanol solution (Kao 1989).
Medical, Ontario, Canada) using a single anterior field at a source-surface distance (SSD) of $80 \mathrm{~cm}$ and with a maximum field size of $35 \times 35 \mathrm{~cm}$. Radiation dose of 60 Gy was delivered as one shot.

\section{Determination of the Degree of conversion (DC\%)}

The assigned specimens were grounded into fine powder. Fifty microgram resin composite powder was mixed with $5 \mathrm{mg}$ of Ispectropic grade (IR) potassium bromide powder $(\mathrm{KBr})$ in 1:10 ratio. The mixture was placed in a pellet maker kit (KBr Product-A-Press, International Crystal Labs, Garfield, NJ, USA) and pressed to obtain a 1-mm-thick pellet. Fourier transform infrared spectrometer (JASCO FT/IR 4600, Japan) (FTIR) was used to determine the DC\%. The spectra were recorded using 24 scans at $4 \mathrm{~cm}^{-1}$ in absorbance mode and 400-4000 $\mathrm{cm}^{-1}$ wavelength. The percentage of unreacted carbon-carbon double bonds $(\% \mathrm{C}=\mathrm{C})$ in the cured composite specimens was determined from the ratio of peak areas of aliphatic $C=C\left(1638 \mathrm{~cm}^{-1}\right)$ against the aromatic component $\left(1608 \mathrm{~cm}^{-1}\right)$, which was used as an internal standard. The underlying peak area was calculated for each peak using a standard baseline technique with the aid of computer software program provided with the spectrometer (JASCO Spectral Analysis, Japan). To obtain the spectrum of the uncured resin composite, the composites paste was directly mixed with the potassium bromide powder in the same ratio described for the cured specimens. The DC\% for each group was determined using the following equation:

$$
\mathrm{DC} \%=1-\left[\frac{\text { abs }(\text { aliphatic } C=C) / \text { abs (aromatic } C=C)}{\text { abs }(\text { aliphatic } C=C) / \operatorname{abs}(\text { aromatic } C=C)] \text { uncured }}\right] \times 100 \text {. }
$$

\section{Radiation exposure of the composite specimens}

After each storage time, half of the specimens from each material were evaluated without being subjected to the radiation exposure dose. The other half was subjected to 60 Gy of gamma radiation a single fraction. Specimens assigned for exposure to radiation were first blot dried then embedded in pink modelling wax sheets. Their top surfaces were flushing with the wax surface. This was done in order to ensure intimate contact with the phantom (a human tissue equivalent material), to minimize radiation errors and to ensure dose homogeneity. Another phantom of $5 \mathrm{~mm}$ thickness was placed above the wax to allow for radiation build-up. Gamma rays radiation was performed with an average of (1.25 MeV) emitted from a cobalt-60 machine (Theraton Phoenix 60 Cobalt Radiotherapy Treatment Unit-Theratronics International, Ltd., Atomic Energy of Canada, Ltd., AECL

\section{Flexural strength (FS) testing}

Specimens were subjected to a three-point bending test in a universal testing machine (Shimadzu 5KN (Autograph AG_X Plus, Japan). Each specimen was placed on a specially fabricated stainless-steel holder that consisted of two vertical rods, acting as supports, mounted parallel to each other above a flat base with the distance of $10 \mathrm{~mm}$ between centers of their apices. Another single stainless-steel rod was attached to the upper jig of the universal testing machine to apply vertical striking force directly on the center of the top surface of the composite specimens. The test was run at crosshead speed of $1 \mathrm{~mm} / \mathrm{min}$ until failure. FS $(\sigma)$, in mega-pascals $(\mathrm{MPa})$, was calculated using the following formula:

$$
\sigma=3 \mathrm{Fl} / 2 \mathbf{b d}^{2}
$$


where $\mathbf{F}$ is the maximum load at the point of fracture (Newton), $\mathbf{l}$ is the distance between the two supports $(10 \mathrm{~mm}), \mathbf{b}$ is the width of specimen measured prior to testing $(2 \mathrm{~mm})$, and $\mathbf{d}$ is the thickness of the specimen measured prior to testing $(2 \mathrm{~mm})$.

\section{Statistical analysis}

Statistical analysis was performed using IBM statistical software for Windows (Version 21). The significance level was set at $P=0.05$. Data was analyzed using Three-Way ANOVA to evaluate the effect of factors "radiation", "resin composite", "storage time" and "radiation $\times$ resin composite $\times$ storage time). One-Way ANOVA followed by Tukey's HSD post hoc test was used for pairwise comparison in resin composites and storage periods. Independent student $t$ test was used to compare between radiation noexposure and radiation exposure groups.

\section{Results}

For the DC\% results, three-way ANOVA (Table 2) showed that factors "radiation", "resin composite", and "storage time" had statistically significant effect on DC\% $(P<0.001)$. On the other hand, factor "radiation $\times$ resin composite $\times$ storage time" revealed no statistically significant difference on the DC\% $(P>0.05)$.

One-way ANOVA showed that for factor radiation exposure (Table 3), there was no statistically significant difference between no-radiation exposure and radiation exposure treatments $(P>0.05)$. Regarding factor resin composite (Table 4), Herculite XRV Ultra revealed the highest statistically significant DC\%, while Grandio showed the least statistically significant value among all tested resin composites $(P<0.05)$. For factor storage time (Table 5 ), there was no statistically significant difference between $3-\mathrm{m}$ and $6-\mathrm{m}$ storage times $(P>0.05)$. Both $3-\mathrm{m}$ and $6-\mathrm{m}$ storage times showed statistically significant higher DC\% compared to 24-h storage time $(P<0.05)$.

For the FS results, three-way ANOVA (Table 6) showed that factors "radiation", "resin composite", "storage time", and "radiation $\times$ resin composite $\times$ storage time" had statistically significant effect on FS of the different resin composites $(P<0.05)$.

Table 2 Three-way ANOVA analyzing the effect of radiation, material, storage, and their interaction on DC\%

\begin{tabular}{lccrr}
\hline Source & $\boldsymbol{d f}$ & Mean Square & \multicolumn{1}{l}{$\boldsymbol{F}$} & \multicolumn{1}{l}{ Sig } \\
\hline Radiation & 1 & 16.035 & 17.867 & $<0.001$ \\
Material & 2 & 194.645 & 216.884 & $<0.001$ \\
Storage & 2 & 94.786 & 105.616 & $<0.001$ \\
$\begin{array}{l}\text { Radiation } \times \text { Material } \times \text { Stor- } \\
\text { age }\end{array}$ & 4 & 0.292 & 0.326 & 0.860 \\
\hline
\end{tabular}

Table 3 Mean \pm standard deviations for the effect of radiation on DC\%

\begin{tabular}{llll}
\hline & & No-exposure & Exposure \\
\hline Grandio & $24-\mathrm{h}$ & $74.0 \pm 0.4$ & $74.4 \pm 0.4$ \\
& $3-\mathrm{m}$ & $75.3 \pm 0.4$ & $76.2 \pm 0.4$ \\
& $6-\mathrm{m}$ & $76.2 \pm 1.7$ & $77.5 \pm 0.4$ \\
Z 250 XT & $24-\mathrm{h}$ & $74.8 \pm 1.1$ & $75.1 \pm 1.0$ \\
& $3-\mathrm{m}$ & $77.3 \pm 1.2$ & $78.1 \pm 1.1$ \\
Herculite XRV Ultra & 6-m & $77.7 \pm 1.2$ & $78.5 \pm 0.4$ \\
& $3-\mathrm{m}$ & $77.8 \pm 0.1$ & $78.3 \pm 1.7$ \\
Total radiation & $80.0 \pm 0.9$ & $81.8 \pm 0.2$ \\
\hline
\end{tabular}

Means with same superscript capital letters for the total radiation are not statistically significant at $P=0.05$

One-way ANOVA showed that for factor radiation (Table 7), radiation exposure showed a statistically significant higher FS $(P<0.05)$. Regarding the factor resin composite (Table 8 ), there was no statistically significant difference between Grandio and Z250 XT $(P>0.05)$, and both materials showed a statistically significant higher FS compared to Herculite XRV Ultra $(P<0.05)$. Regarding the factor storage time (Table 9), there was a statistically significant difference between the different storage periods $(P<0.05)$. 24-h storage time showed the highest value, while 6-m storage showed the least FS value.

\section{Discussion}

Patients receiving radiotherapy in the head and neck region usually become higher-risk candidates of developing more dental diseases, and thus the selection of dental restorative materials is of paramount importance in order to prevent any deleterious interactions between the incident radiotherapy on the properties of the restorative material. In this regard, the testing of different properties

Table 4 Mean \pm standard deviations for the effect of material on DC\%

\begin{tabular}{lllll}
\hline & & Grandio & Z250XT & Herculite XRV Ultra \\
\hline No-radiation & $24-\mathrm{h}$ & $74.0 \pm 0.4$ & $74.8 \pm 1.1$ & $77.8 \pm 0.1$ \\
$\quad$ exposure & $3-\mathrm{m}$ & $75.3 \pm 0.4$ & $77.3 \pm 1.2$ & $80.0 \pm 0.9$ \\
& $6-\mathrm{m}$ & $76.2 \pm 1.7$ & $77.7 \pm 1.2$ & $82.2 \pm 1.1$ \\
Radiation expo- & $24-\mathrm{h}$ & $74.4 \pm 0.4$ & $75.1 \pm 1.0$ & $78.3 \pm 1.7$ \\
$\quad$ sure & $3-\mathrm{m}$ & $76.2 \pm 0.4$ & $78.1 \pm 1.1$ & $81.8 \pm 0.2$ \\
& $6-\mathrm{m}$ & $77.5 \pm 0.4$ & $78.5 \pm 0.4$ & $83.0 \pm 1.0$ \\
Total material & & $75.6 \pm 1.4^{\mathrm{A}}$ & $76.9 \pm 1.8^{\mathrm{B}}$ & $80.5 \pm 2.3^{\mathrm{C}}$ \\
\hline
\end{tabular}

Means with same superscript capital letters for the total material are not statistically significant at $P=0.05$ 
Table 5 Mean \pm standard deviations for the effect of storage on DC\%

\begin{tabular}{lllll}
\hline & & 24-h & 3-m & 6-m \\
\hline No-radiation exposure & Grandio & $74.0 \pm 0.4$ & $75.3 \pm 0.4$ & $76.2 \pm 1.7$ \\
& Z 250 XT & $74.8 \pm 1.1$ & $77.3 \pm 1.2$ & $77.7 \pm 1.2$ \\
Radiation exposure & Herculite XRV Ultra & $77.8 \pm 0.1$ & $80.0 \pm 0.9$ & $82.2 \pm 1.1$ \\
& Grandio & $74.4 \pm 0.4$ & $76.2 \pm 0.4$ & $77.5 \pm 0.4$ \\
Total storage & Z 250 XT & $75.1 \pm 1.0$ & $78.1 \pm 1.1$ & 83.1 \\
\hline
\end{tabular}

Mean with same superscript capital letters for the total storage are not statistically significant at $P=0.05$

Table 6 Three-way ANOVA for the effect of radiation, material, storage, and their interaction on FS

\begin{tabular}{lccrl}
\hline Source & $\boldsymbol{d f}$ & Mean Square & $\boldsymbol{F}$ & Sig \\
\hline Radiation & 1 & $15,667.727$ & 311.180 & $<0.001$ \\
Material & 2 & $70,215.157$ & 1394.560 & $<0.001$ \\
Storage & 2 & $687,849.724$ & $13,661.544$ & $<0.001$ \\
$\begin{array}{l}\text { Radiation } \times \text { Mate- } \\
\text { rial } \times \text { Storage }\end{array}$ & 4 & 7729.015 & 153.508 & $<0.001$ \\
\hline
\end{tabular}

Table 7 Mean \pm standard deviations for the effect of radiation on FS

\begin{tabular}{lccc}
\hline & \multicolumn{1}{c}{$\begin{array}{c}\text { No-radiation } \\
\text { exposure }\end{array}$} & Radiation exposure \\
\hline Grandio & $24-\mathrm{h}$ & $160.5 \pm 8.6$ & $216.6 \pm 10.3$ \\
& $3-\mathrm{m}$ & $62.4 \pm 5.6$ & $118.9 \pm 7.8$ \\
Z 250 XT & $6-\mathrm{m}$ & $51.2 \pm 6.8$ & $27.3 \pm 5.8$ \\
& $24-\mathrm{h}$ & $179 \pm 8.4$ & $219.1 \pm 7.2$ \\
Herculite XRV Ultra & $3-\mathrm{m}$ & $29.2 \pm 5.4$ & $58 \pm 7.4$ \\
& $6-\mathrm{m}$ & $39.1 \pm 3.9$ & $29.9 \pm 5.2$ \\
Total radiation & $3-\mathrm{m}$ & $33.7 \pm 6.8 \pm 10.3$ & $119.5 \pm 9.2$ \\
& $6-\mathrm{m}$ & $19.6 \pm 5.7$ & $24.3 \pm 5.6$ \\
& & $79.3 \pm 59.2^{\mathrm{A}}$ & $18.7 \pm 3.5$ \\
\hline
\end{tabular}

Means with same superscript capital letters for the total radiation are not statistically significant at $P=0.05$ of resin composite materials that were exposed to radiation dose is thus mandatory (Toth et al. 1991).

The results of this study rejected the null hypothesis, as factors "radiation", "material", and "storage time" had significant effects on both DC\% and FS of the tested resin composites.

From the results of this study, factor radiation exposure showed no statistically significant effect on the DC\% of the different resin composite, regardless to the different storage times (Table 3). The DC\% is a material dependent property (Par et al. 2019; Erdemir et al. 2013). Variation in the chemistry and formulations of organic matrix and different filler features such as mass fraction, density, and particle size, shape, and distribution; were found to contribute to the variable significant differences in the final $\mathrm{DC} \%$ of the investigated resin composites. (Abed et al. 2015; Turssi et al. 2005; Amirouche-Korichi et al. 2009). When resin composites were light-cured, the DC\% could be expected to reach its maximum value before exposure to the therapeutic radiation dose (Cruz et al. 2008), and that no changes in the chemical structure of the investigated resin composites could occur following radiation exposure. The results of this study came in agreement with the results of Cruz et al. (2008). They reported that there was no change detected in the DC\% of the studied resin composites after exposure to different doses of radiation. On the other hand, the results of this study disagreed with the studies of Hsiue and Chang (1993), Campos et al. (2015), Cruz et al. (2009) and Haque et al.

Table 8 Mean \pm standard deviations for the effect of material on FS

\begin{tabular}{lcccc}
\hline & & Grandio & Z250XT & Herculite XRV Ultra \\
\hline No-radiation exposure & $24-\mathrm{h}$ & $160.5 \pm 8.6$ & $179 \pm 8.4$ & $138.8 \pm 10.3$ \\
& $3-\mathrm{m}$ & $62.4 \pm 5.6$ & $29.2 \pm 5.4$ & $33.7 \pm 6.1$ \\
Radiation exposure & $6-\mathrm{m}$ & $51.2 \pm 6.8$ & $39.1 \pm 3.9$ & $19.6 \pm 5.7$ \\
& $24-\mathrm{h}$ & $216.6 \pm 10.3$ & $219.1 \pm 7.2$ & $119.5 \pm 9.2$ \\
Total material & $3-\mathrm{m}$ & $118.9 \pm 7.8$ & $58 \pm 7.4$ & $24.3 \pm 5.6$ \\
\hline
\end{tabular}

Means with same superscript capital letters for the total material are not statistically significant at $P=0.05$ 
Table 9 Mean \pm standard deviations for the effect of storage on FS

\begin{tabular}{llcrr}
\hline & & 24-h & 3-m & 6-m \\
\hline No-radiation exposure & Grandio & $160.5 \pm 8.6$ & $62.4 \pm 5.6$ & $51.2 \pm 6.8$ \\
& Z 250 XT & $179 \pm 8.4$ & $29.2 \pm 5.4$ & $39.1 \pm 3.9$ \\
Radiation exposure & Herculite XRV Ultra & $138.8 \pm 10.3$ & $33.7 \pm 6.1$ & $19.6 \pm 5.7$ \\
& Grandio & $216.6 \pm 10.3$ & $118.9 \pm 7.8$ & $27.3 \pm 5.8$ \\
Total storage & Z 250 XT & $219.1 \pm 7.2$ & $58 \pm 7.4$ & $29.9 \pm 5.2$ \\
\hline
\end{tabular}

Means with same superscript capital letters for the total storage are not statistically significant at $P=0.05$

(2001). They reported significant changes in the final DC\% of the tested photo-polymerized resin composites after exposure to different doses of the ionizing radiations. These disagreements could be contributed partly to the difference in resin composites' formulations used and partly to the difference in radiation doses, into which some studies used lower doses of radiation (Campos et al. 2015; Cruz et al. 2009), while the other studies used higher radiation doses than the ones used in the present study (Hsiue and Chang 1993; Haque et al. 2001).

It was reported that therapeutic radiation could induce a post-cure reaction, which occurred because some portions of the free radicals generated during composite polymerization could be trapped within the heterogeneous network and might persisted for extended periods (Burtscher 1993). Furthermore, resin composites' DC\% could be continued after light-curing, but at a slower rate (Schneider et al. 2006). Such contradiction could be associated with the different tested resin composite materials in these studies. The possibility of the incident gamma radiation beam to yield any molecular disruption might be overcame by the high energy created by carbon-tocarbon single bond in the polymeric network (Arener 1974). Additionally, this could be owed to the process by which the gamma radiation is absorbed by the inorganic filler particles and the radiosensitive chemical groups in the resin composites. As the gamma radiation will spread within the resin composites into their organic resin matrix leading to excitation and ionization of the matrix and development of coupled reactive species (chemical reagents starters or initial chemical reagents). Due to the limited molecular mobility inside the photo-polymerized resin composite materials network, the chemical reagents would only link among themselves creating new chains or link with and stabilize the closer chemical groups (Hsiue and Chang 1993; Haque et al. 2001; Cruz et al. 2009; Behr et al. 2005). This might affect other mechanical properties of the resin composites but would not increase their DC\% (Cruz et al. 2008).
Regarding the effect of factor radiation exposure on the flexure strength of the different resin composites, radiation exposure resulted in statistically significant higher FS values (Table 7). Flexure strength is a structurally sensitive property that could be easily affected by lattice defects and voids. Novais et al. (2015) found some decrease of FS after the irradiation protocol and reported that explanation of their results was difficult to be addressed. Catelan et al. (2008) evaluated the effect of radiotherapy on FS of resin composite, and they demonstrated that the flexural strength had a tendency toward gradual increase in radiation values up to a dose of 50 Gy while it started to decline with higher doses, such as $60 \mathrm{~Gy}$. Consequently, ionizing radiation with doses ranging from 25 to 200 Gy was found to be capable of modifying the microstructure of dental composites and improve their properties as well (Behr et al. 2005; Vaishnavi et al. 2010). It was reported that radiation exposure might be able to reorganize the residual chemical groups of low molecular weight inside the polymer matrix to obtain a beneficial effect (Von-Fraunhofer et al. 1989), which in turn might explain the significant increase in FS in the present study. Moreover, Vaishnavi et al. (2010) concluded that mechanical properties of dental composites irradiated with higher doses would further optimize the material properties, which came in agreement with the results of the present study.

On the other hand, the results of this study disagreed with the study of Haque et al. (2001). They found that FS was not improved by the exposure to gamma radiation. The difference in resin composites used might be the reason of such disagreement.

Regarding the effect of factor resin composite material on the DC\%, Herculite XRV Ultra had a significantly higher DC\% values compared to Z250 XT and Grandio (Table 4). This difference in the compositions of the tested resin composites in this study could play a major role in the difference in the $\mathrm{DC} \%$ values of the tested composites (Abed et al. 2015). It was reported that different monomers exhibit different DC\%, in the following increasing 
order: BIS-GMA $<$ BIS-EMA $<$ UDMA $<$ TEGDMA (Sideridou et al. 2002). BIS-GMA, the strong intramolecular hydrogen bonding of its hydroxyl groups $(-\mathrm{OH})$ and the presence of rigid aromatic nuclei interactions given by the aromatic rings in its structure are the reasons for being the most viscous and least flexible monomer. On the other hand, UDMA is a less viscous, and a more flexible monomer compared to BIS-GMA and thus has increased the reactivity and higher DC\% was obtained. This is because of the weak hydrogen bond of its amine group compared to that of the hydroxyl groups present in BIS-GMA (Khatri et al. 2003). Also, characteristic chain transfer reactions might exist due to the presence of the amine groups in its urethane structure of UDMA, which could provide an alternative path for the continuation of polymerization and hence increase the monomer conversion (Sideridou et al. 2002). Regarding the TEGDMA, it has the least viscosity and the highest DC\% among the different monomer systems and considered as the main contributor for polymerization (Floyd and Dickens 2006; Sgarbi et al. 2010). TEGDMA has a better plasticizing effect on BIS-GMA than UDMA and BIS-EMA, which could result in a synergistic effect of components of BIS-GMA/TEGDMA organic matrix mixture on the polymerization rate (Sideridou et al. 2002). Herculite XRV Ultra contains a higher TEGDMA/BIS-GMA ratio, which could enhance its flowable consistency (Alshali et al. 2013). On the other hand, Z250 XT contains the high molecular weight BIS-EMA monomer in addition to BIS-GMA and UDMA monomers. BIS-EMA is a bulky monomer with a stiff central phenyl ring core that might enhance the mechanical performance of the material, yet it can significantly restrict the mobility of UDMA monomers and decrease their reactivity and ultimate conversion value (Alshali et al. 2013).

Additionally, Herculite XRV Ultra has the least filler wt\% compared to Grandio and Z250 XT. Increasing the filler wt\% in the resin composite material resulted in a decrease in DC\% (Halvorson et al. 2009). Light penetration was found to be more in case of low-filled composites than denser ones. Light transmission within the resin matrix could be considerably attenuated by the frequent scattering caused by the densely distributed fillers within the resin matrix of the resin composites (Turssi et al. 2005). Additionally, high filler load might have contributed to lower DC\% values by decreasing the composite's translucency (Bucuta and Ilie 2014). Correspondingly, Grandio resin composite exhibits the higher filler loading among all tested resin composites. Increasing amounts of the inorganic filler could increase the overall surface area contacted by the polymerizing matrix phase. Therefore, the polymer mobility in its immediate vicinity could be restricted (Halvorson et al. 2009; Rastelli et al. 2012), reducing the linking potential between the polymer chains which would finally result in lower monomer conversion results (Shah and Stansbury 2014).

On the other hand, there was a statistically insignificant difference between Z250XT and Grandio in their FS, which both materials showed a statistically significant higher FS compared to Herculite XRV Ultra (Table 8). According to Kim et al. (2002), the filler system characteristics have a great influence on the different mechanical properties of resin composites. Moreover, increasing the filler content of a resin composite could lead to an increase of the Young's modulus, thus its resistance to deformation improved (Beun et al. 2007). Generally, strength and fracture energy increased by the presence of a closely spaced disperse phase in a brittle material. In addition, the presence of filler particles in the crack path resulted in cracks pinning (Belli et al. 2014), which led to a significant toughening mechanism in the nanocomposites (Albdiry et al. 2013). On the contrary, Park et al 2014, found a low correlation between FS and filler content, highlighting the fact that FS depended more on the presence of internal defects such as cracks or voids that were generated during manufacturing process of the dental composites (Mecholsky 1995; Bona et al. 2003). Grandio and Z250 XT contain higher filler wt\% compared to Herculite XRV Ultra, according to their manufacturers. Furthermore, the presence of pre-polymerized fillers in Herculite XRV Ultra might contribute to lower FS of the material, which was observed in previous studies (Randolph et al. 2016; Blackham et al. 2009). Pre-polymerized fillers lack active binding sites and are difficult to silanize resulting in poor integration in the resin matrix (Randolph et al. 2016). The bond between pre-polymerized fillers and the polymer matrix is thus regarded as a weak spot, capable of causing reduction in strength properties (Ferracane 1995). Grandio showed a higher yet statistically insignificant difference when compared to Z250 XT, which might indicate that the effect of its higher filler wt\% was offset by other factors. The presence of aromatic cycles in monomers like Bis-GMA and Bis-EMA in Z250 XT composite, resulting in reduced cyclization and increased cross-linking in the polymer, hence the mechanical properties could be improved (Sideridou et al. 2002). Moreover, the presence of zirconium fillers and small sized filler particles might contribute to increased mechanical strength due to increased filler surface area to the filler particle content (Halvorson et al. 2009).

For the effect of factor storage time on the DC\% of the different resin composites, the results showed that both 3-m and 6-m storage time exhibited statistically significant higher DC\% values compared to 24-h storage time (Table 5). An increase in the DC\% was observed over 
time (Mohamad et al. 2007; Ghavami-Lahiji et al. 2018; Tonetto et al. 2013), with the highest value was found at 7 days after the initial light curing of resin composites post-curing (Tonetto et al. 2013). Leprince et al. 2009, showed that the post-cure polymerization could start within the 24-h following light curing, but it continued in a slower rate. In this regard, the conclusion was raised, which suggested that the polymerization reaction might not be terminated by the end of the light curing cycle. However, the residual radicals could convert the double bonds over a prolonged time leading to an increase in the DC\% (Zissis et al. 2008). As the polymerization reaction progresses, both propagation and termination reactions became of limited diffusion due to the restriction of the pendant groups' mobility, which occurred via developing a highly cross-linked network polymer, in a process known as auto-deceleration. As a result, some radicals got trapped within the heterogeneous network and can persist for extended periods (Burtscher 1993; Elliott et al. 2001). However, these trapped radicals could encounter pendant groups with time, resulting in additional conversion (Schneider et al. 2006). Moreover, there were other 'trapped' active components in the polymer network in addition to the free radicals, such as free monomers, pendant double bonds, and photo-initiators that might have a positive significant effect on the DC\% of the resin composites (Leprince et al. 2013). Final conversion might therefore be controlled by diffusion limitations of the reacting groups and not by the amount of the uncured monomers (Lovell et al. 1999). In order to drive small molecules to diffuse into the polymer matrix and make such radicals able to react with any remaining double bonds within the network, studies suggested that inducing a swelling within the matrix of the tested composites by a solvent, which could promote a diffusion reaction and increased the mobility of the system (Leprince et al. 2009, 2010; Truffier-Boutry et al. 2006). Neves et al. (2013), compared the effect of water and ethanol treatments, and they concluded that the reduction of the residual monomer content was found to be higher with ethanol solutions compared to water, which emphasized the effect of the storage media on increasing the diffusion reaction in the stored resin composite. Ethanol act as solvent for resin monomer, and could successfully penetrate the polymer matrix, expanding the space between polymer chains and accelerated water sorption to the polymer matrix. This could promote residual monomer diffusion from the polymer (Fujii et al. 2002). The increased effect of ethanol penetration into the polymer matrix could be attributed to its solubility parameter value which was found to be closer to that of the monomer than that of the water solubility parameter. Correspondingly, the higher proportion of ethanol in the used solution might lead to a more significant reduction of the residual monomer content by diffusion (Neves et al. 2013).

Nevertheless, the results of the current study showed that there was a statistically significant difference between the three storage periods for the FS of the investigated composites. The 24-h revealed the highest mean FS values, while $6-\mathrm{m}$ showing the least statistically significant values (Table 9). The deterioration tendency of FS after storage in alcohol has also been observed in previous studies (Schmidt and Ilie 2012; Drummond et al. 2004; Zhang and Xu 2008), which could be related to the increased solubility of the resin matrix in alcohol. This could enable the solution to penetrate easier into the matrix, thus allowed for greater access to the filler, leading to their leaching and faster deterioration of resin composites (Drummond et al. 2004; Schmidt and Ilie 2012). The FS is much more impaired by more eluted monomers caused by the higher penetration capacity of the alcohol (Zhang and $\mathrm{Xu}$ 2008). Moreover, nanosized fillers have large surface to volume ratio which was observed to increase the water uptake of resin composites (Curtis et al. 2008). This might contribute to the great impact of the alcohol solution. On the other hand, Schwartz and Söderholm (2004) have discussed the possibility that fine filler particles might attribute to a lower plasticizing effect. The low inter-particle spacing present between smaller particles might lead to a reduced diffusion of plasticizing agents (Schwartz and Söderholm 2004). Sideridou et al. (2009) came in disagreement with the results of this study, as they found that storage in ethanol had no impact on the flexure strength of the tested resin composites. Although one of their tested composites was a nanohybrid one, its filler concentration (77 wt\%) was lower than the filler concentration of the resin composites used in this study. Another cause for the disagreement was the storage time, which was from 3 to 6 times more than the storage time in the study of Sideridou et al.

Composites with increased cross-link density and low residual monomer have been shown to exhibit a greater wear resistance, hardness, and flexural strength (Ferracane et al. 1997; Ferracane and Greener 1986). Campos et al. (2015), found that ionizing radiation can induce a post cure reaction, which consequently resulted in an increase in both the DC\% and FS of resin composites. This was come partly in agreement and partly in disagreement with the results of this study, as radiation exposure did not affect the DC\%, while it had a positive significant effect on the FS. The DC\% of resin composite system was generally believed to affect the mechanical properties of resin composites (Prasanna et al. 2007; Krämer et al. 2008). There was a common assumption that the higher the conversion of double bonds, the 
greater the mechanical strength of the resin composites (Lovell et al. 2003). This was not confirmed in the present study, as there was no significant correlation between the DC\% of the different resin composites and their FS results (Pearson Correlation $=0.188$ and $P=0.76$ ). Variation in the relative amounts of different monomers in the matrix could have a varying effect on the mechanical properties of resin composites (Peutzfeldt 1997). The amount of inorganic filler is a main determinant of FS in the highly filled composite. For this reason, it was reported that to compare the DC\% and the FS, the tested resin composites should contain the approximate amount of filler (Lee et al. 2006).

\section{Conclusions}

Under the limitations of this study, the following conclusions could be suggested:

1. Radiation exposure had no impact on the final DC\% of the investigated resin composites, while it had a positive impact effect on their FS.

2. Resin composites with different filler loadings affected the DC\% and FS of the tested resin composites.

3. Storage in ethanol positively influenced the DC\%, but it weakened the tested resin composites mechanically, as increasing the storage time in ethanol induced further decreasing in the FS of the tested resin composites.

Nevertheless, it becomes of importance to conduct clinical studies to evaluate the effect of radiation exposure, not only on the soft tissues and teeth, but also on the performance of the existing restorations. This could help clinicians to take the appropriate decision, whether to replace the existing restorations after the exposure to radiation in the head-and-neck region, or try to find a more conservative way, as repair, to treat the failed ones.

\section{Abbreviations \\ DC\%: Degree of conversion; FS: Flexural strength; BIS-GMA: Bisphenol A-glycidyl methacrylate; UDMA: Urethane dimethacrylate; BIS-EMA: Bisphenol A ethoxylate dimethacrylate; PEGDMA: Polyethylene glycol dimethacrylate; TEGDMA: Tetraethylene glycol dimethacrylate.}

\section{Acknowledgements}

Not applicable

\section{Authors' contributions}

$\mathrm{MI}$ and FE developed the original idea, main conception and constructed the study design. FE carried out the statistical analysis for the presented results data, contributed to the interpretation of the results, contributed to discussion writing and revised the final presented manuscript. MZ participated in revising the manuscript draft. AA developed the methodology of specimens' exposure to radiation and revised the part of the methodology and the discussion related to effects of exposure to radiation. LM participated in executing the study tests, contributed to results interpretation, contributed in writing the discussion and participated in revising the manuscript draft. RT contributed in construction of the study design, executed the study methodology, participated in results interpretation and presented the discussion of the results obtained for revision. All authors read and approved the final manuscript, except Professor Mokhtar N. Ibrahim, as he passed away before reading and revising the manuscript. All authors read and approved the final manuscript.

\section{Funding}

The authors declare that this research was not funded by any institution or organization. This study was a part of the Ph.D. thesis of Ragia M. Taher in the partial fulfilment for the requirements of the Doctor's Degree in Operative Dentistry.

\section{Availability of data and materials}

The authors declare that the data supporting the findings of this study are available within the article.

\section{Declarations}

Ethics approval and consent to participate

Not applicable.

\section{Consent for publication}

Not applicable.

\section{Competing interests}

There are no conflicts of interest.

\section{Author details}

${ }^{1}$ Restorative and Dental Materials Department, National Research Centre, Bohouth Street, Dokki, Cairo, Egypt. ${ }^{2}$ Oncology Department, Faculty of Medicine, Ain Shams University Cairo, Cairo, Egypt. ${ }^{3}$ Faculty of Dentistry, Ain Shams University, Cairo, Egypt.

Received: 13 July 2021 Accepted: 3 August 2021

Published online: 12 August 2021

\section{References}

Abed YA, Sabry H, Alrobeigy NA (2015) Degree of conversion and surface hardness of bulk-fill composite versus incremental-fill composite. Tanta Dent J 12:71-80

Albdiry MT, Yousif BF, Ku H (2013) Fracture toughness and toughening mechanisms of unsaturated polyester-based clay nanocomposites. In: The 13th international conference on fracture (ICF) 16-21 June, Beijing

Alshali RZ, Silikas N, Satterthwaite JD (2013) Degree of conversion of bulk-fill compared to conventional resin-composites at two time intervals. Dent Mater 29(9):e213-e217

Amirouche-Korichi A, Mouzali M, Watts DC (2009) Effects of monomer ratios and highly radiopaque fillers on degree of conversion and shrinkagestrain of dental resin composites. Dent Mater 25(11):1411e8

Arener SH (1974) Introduction to physical metallurgy, 1st edn. McGraw-Hill, London

Barnett GC, West CM, Dunning AM, Elliott RM, Coles CE, Pharoah PD, Burnet NG (2009) Normal tissue reactions to radiotherapy: towards tailoring treatment dose by genotype. Nat Rev Cancer 9(2):134-142

Behr M, Martin R, Faltermeier A, Handel G (2005) Electron beam irradiation of dental composites. Dent Mater 21(9):804-810

Belli R, Kreppel S, Petschelt A, Hornberger H, Boccaccini AR, Lohbauer U (2014) Strengthening of dental adhesives via particle reinforcement. J Mech Behav Biomed Mater 37:100-108

Beun S, Glorieux T, Devaux J, Vreven J, Leloup G (2007) Characterization of nanofilled compared to universal and microfilled composites. Dent Mat 23(1):51-59

Blackham JT, Vandewalle KS, Lien W (2009) Properties of hybrid resin composite systems containing pre-polymerized filler particles. Oper Dent 34:697-702 
Bona AD, Anusavice KJ, De Hoff PH (2003) Weibull analysis and flexural strength of hot-pressed core and veneered ceramic structures. Dent Mater 9(7):662-629

Brandeburski SBN, Della Bona A (2018) Effect of ionizing radiation on properties of restorative materials. Dent Mater 34(2):221-227

Bucuta S, Ilie N (2014) Light transmittance and micro-mechanical properties of bulk fill vs. conventional resin-based composites. Clin Oral Investig 18(8):1991-2000

Burtscher P (1993) Stability of radicals in cured composite materials. Dent Mater 9(4):218-221

Campos L, Boaro L, Santos L, Duclerc P, Ab L (2015) Influence of ionizing radiation on the mechanical properties of BisGMA/TEGDMA based experimental resin. Rad Phys Chem 115:30-35

Catelan A, Padilha AC, Salzedas LM, Coclete GA, dos Santos PH (2008) Effect of radiotherapy on the radiopacity and flexural strength of a composite and resin. Acta Odontol Latinoam 21(2):159-162

Cruz AD, Sinhoreti MA, Ambrosano G, Rastelli A, Bagnato V, Bóscolo F (2008) Effect of therapeutic dose $X$ rays on mechanical and chemical properties of esthetic dental materials. Mat Res 11:313-318

Cruz AD, Almeida SM, Rastelli ANS, Bagnato VS, Byscolo FN (2009) FTIR Spectroscopy assessment of aesthetic dental materials irradiated with low-dose therapeutic ionizing radiation. Las Phys 19:461-467

Curtis AR, Shortall AC, Marquis PM, Palin WM (2008) Water uptake and strength characteristics of a nanofilled resin-based composite. J Dent 36:186-193

Drummond JL, Andronova K, Al-Turki LI, Slaughter LD (2004) Leaching and mechanical properties characterization of dental composites. J Biomed Mater Res B: Appl Biomater 71:172-180

Elliott JE, Lovell LG, Bowman CN (2001) Primary cyclization in the polymerization of bis-GMA and TEGDMA: a modelling approach to understanding the cure of dental resins. Dent Mater 17(3):221-229

Erdemir U, Yildiz E, Eren MM, Ozsoy A, Topcu FT (2013) Effects of polishing systems on the surface roughness of tooth-colored materials. J Dent Sci 8(2):160-169

Ferracane JL (1995) Current trends in dental composites. Crit Rev Oral Biol Med $6(4): 302-318$

Ferracane JL, Greener EH (1986) The effect of resin formulation on the degree of conversion and mechanical properties of dental restorative resins. $J$ Biomed Mater Res 20(1):121-131

Ferracane JL, Mitchem JC, Condon JR, Todd R (1997) Wear and marginal break down of composites with various degrees of cure. J Dent Res 76(8):1508-1516

Ferracane JL, Berge HX, Condon JR (1998) In vitro aging of dental composites in water-effect of degree of conversion, filler volume, and filler/matrix coupling. J Biomed Mater Res 42(3):465-472

Filtek Z250 XT Nano Hybrid Universal Restorative: Technical data sheet (TDS), $3 \mathrm{M}$ ESPE, St. Paul, MN, USA

Floyd CJE, Dickens SH (2006) Network structure of BisGMA- and UDMA-based resin systems. Dent Mater 22(12):1143-1149

Fujii K, Arikawa H, Kanie T, Kamiunten O, Miura K (2002) Effect of ethanol on the hardness and relaxation modulus of experimental photoactivated soft lining materials stored in aqueous solutions. J Oral Rehabil 29(8):770-776

Ghavami-Lahiji M, Firouzmanesh M, Bagheri H, Jafarzadeh Kashi TS, Razazpour F, Behroozibakhsh M (2018) The effect of thermocycling on the degree of conversion and mechanical properties of a microhybrid dental resin composite. Restor Dent Endod 43:12

Grandio: Material safety data sheet (MSDS), Voco, Guxhaven, GMBH- Germany

Halvorson RH, Erickson RL, Davidson CL (2009) The effect of filler and silane content on conversion of resin-based composite. Dent Mater 19:327-333

Haque S, Takinami S, Watari F, Khan MH, Nakamura M (2001) Radiation effects of carbon ions and gamma ray on UDMA based dental resin. Dent Mater J 20(4):325-338

Hsiue GH, Chang HK (1993) The effects of radiation modified silica and monomeric diluents on the properties of dental composite resins. Appl Macromol Chem 209:63-77

Kao EC (1989) Influence of food-simulating solvents on resin composites and glass-ionomer restorative cement. Dent Mater 5(3):201-208

Khatri CA, Stansbury JW, Schultheisz CR, Antonucci JM (2003) Synthesis, characterization and evaluation of urethane derivatives of Bis-GMA. Dent Mater 19:584-588
Kim KH, Ong JL, Okuno O (2002) The effect of filler loading and morphology on the mechanical properties of contemporary composites. J Prosthet Dent 87(6):642-649

Krämer N, Lohbauer U, García-Godoy F (2008) Light curing of resin-based composites in the LED era. Am J Dent 21:135-144

Lee SH, Pae A, Kim SH (2006) A comparative study between degree of conversion and flexural strength of composite resins. J Korean Acad Prosthodont 44(3):333-342

Leprince J, Lamblin G, Truffier-Boutry D, Demoustier-Champagne S, Devaux J, Mestdagh $\mathrm{M}$ et al (2009) Kinetic study of free radicals trapped in dental resins stored in different environments. Acta Biomater 5:2518-2524

Leprince JG, Lamblin G, Devaux J, Dewaele M, Mestdagh M, Palin WM, Gallez B, Leloup G (2010) Irradiation modes'impact on radical entrapment in photoactive resins. J Dent Res 89:1494-1498

Leprince JG, Palin WM, Hadis MA, Devaux J, Leloup G (2013) Progress in dimethacrylate-based dental composite technology and curing efficiency. Dent Mater 29:139-156

Lovell LG, Newman SM, Bowman CN (1999) The effects of light intensity, temperature and Co-monomer composition on the polymerization behavior of dimethacrylate dental resins. J Dent Res 78(8):1469-1476

Lovell LG, Newman SM, Donaldson MM, Bowman CN (2003) The effect of light intensity on double bond conversion and flexural strength of a model, unfilled resin. Dent Mater 19:458-465

Mecholsky JJ Jr (1995) Fracture mechanics principles. Dent Mater 11:111-112

Mohamad D, Young RJ, Mann AB, Watts DC (2007) Postpolymerization of dental resin composite evaluated with nano-indentation and microRaman spectroscopy. Arch Orofac Sci 2:26-31

Neves CB, Lopes LP, Ferrão HF, Miranda JP, Castro MF, Bettencourt AF (2013) Ethanol post-polymerization treatment for improving the biocompatibility of acrylic reline resins. Biomed Res Int 2013:10

Novais V, Simamoto-Júnior P, Rodrigues R, Roscoe M, Valdivia A, Soares C (2015) Effect of irradiation on the mechanical behavior of restorative materials. Rev Odontol Bras Central 24:44-48

Nutting C (2016) Radiotherapy in head and neck cancer management: United Kingdom National Multidisciplinary Guidelines. J Laryngol Otol 130(2):S66-S67

Par M, Spanovic N, Tauböck T, Attin T, Tarle Z (2019) Degree of conversion of experimental resin composites containing bioactive glass 45S5: the effect of post-cure heating. Sci Rep 9(1):17245

Park JK, Lee GH, Kim JH, Park MG, Ko CC, Kim HI, Kwon Y (2014) Polymerization shrinkage, flexural and compression properties of low-shrinkage dental resin composites. Dent Mater j 33:104-110

Peutzfeldt A (1997) Resin composite in dentistry: the monomer systems. Eur J Oral Sci 105:97-116

Prasanna N, Pallavi Y, Kavitha S (2007) Degree of conversion and residual stress of preheated and room temperature composites. Ind J Dent Res 18:173-176

Randolph LD, Palin WM, Leloup G, Leprince JG (2016) Filler characteristics of modern dental resin composites and their influence on physicomechanical properties. Dent Mater 32(12):1586-1599

Rastelli AN, Jacomassi DP, Faloni APS, Queiroz TP, Rojas SS, Bernardi MIB, Bagnato VS, Hernandes AC (2012) The filler content of the dental composite resins and their influence on different properties. Microsc Res Tech 75:758-765

Schmidt C, Ilie N (2012) The mechanical stability of nano-hybrid composites with new methacrylate monomers for matrix compositions. Dent Mater 28(2):152-159

Schneider LF, Consani S, Ogliari F, Correr AB, Sobrinho LC, Sinhoreti MA (2006) Effect of time and polymerization cycle on the degree of conversion of a resin composite. Oper Dent 31(4):489-495

Schwartz JI, Söderholm KJ (2004) Effects of filler size, water, and alcohol on hardness and laboratory wear of dental composites. Acta Odontol Scand 62:102-106

Sgarbi SC, Pereira SK, Martins JMH, Oliveira MAC, Mazur RF (2010) Degree of conversion of resin composites light activated by halogen light and LED analyzed by ultraviolet spectrometry. Rev Clín Pesq Odontol 6:223-230

Shah PK, Stansbury JW (2014) Role of filler and functional group conversion in the evolution of properties in polymeric dental restoratives. Dent Mater 30(5):586-593 
Sideridou I, Tserki V, Papanastasiou G (2002) Effect of chemical structure on degree of conversion in light-cured dimethacrylate based dental resins. Biomaterials 23:1819-1829

Sideridou ID, Karabela MM, Micheliou CN, Karagiannidis PG, Logothetidis S (2009) Physical properties of a hybrid and a nanohybrid dental lightcured resin composite. J Biomater Sci Polym Ed 20(13):1831-1844

Tonetto MR, Pinto SC, Rastelli Ade N, Borges AH, Saad JR, Pedro FL et al (2013) Degree of conversion of polymer-matrix composite assessed by FTIR analysis. J Contemp Dent Pract 14:76-79

Toth BB, Martin JW, Fleming TJ (1991) Oral and dental care associated with cancer therapy. Cancer Bull 43:397-402

Truffier-Boutry D, Demoustier-Champagne S, Devaux J, Biebuyck JJ, Mestdagh M, Larbanois P, Leloup G (2006) A physico-chemical explanation of the post-polymerization shrinkage in dental resins. Dent Mater 22:405-412

Turssi C, Ferracane J, Vogel K (2005) Filler features and their effects on wear and degree of conversion of particulate dental resin composites. Biomaterials 26:4932e7

Vaishnavi C, Kavitha S, Lakshmi NL (2010) Comparison of the fracture toughness and wear resistance of IRCs cured by conventional postcuring methods and electron beam irradiation. J Cons Dent 13:152-155
Von-Fraunhofer JA, Curtis P, Sharma S, Farman AG (1989) The effects of gamma radiation on the properties of composite restorative resins. J Dent 17:177-183

Wu W, McKinney J (1982) Influence of chemicals on wear of dental composites. J Dent Res 61(10):1180-1183

Yucel B, Akkaş EA, Okur Y, Eren AA, Eren MF, Karapinar H, Babacan NA, Kiliçkap S (2014) The impact of radiotherapy on quality of life for cancer patients: a longitudinal study. Support Care Cancer 22(9):2479-2487

Zhang Y, Xu J (2008) Effect of immersion in various media on the sorption, solubility, elution of unreacted monomers, and flexural properties of two model dental composite compositions. J Mater Sci Mater Med 19:2477-2483

Zissis A, Yannikakis S, Polyzois G, Harrison A (2008) A long term study on residual monomer release from denture materials. Eur J Prosthodont Restor Dent 16:81-84

\section{Publisher's Note}

Springer Nature remains neutral with regard to jurisdictional claims in published maps and institutional affiliations.

\section{Submit your manuscript to a SpringerOpen ${ }^{\circ}$ journal and benefit from:}

- Convenient online submission

- Rigorous peer review

- Open access: articles freely available online

- High visibility within the field

- Retaining the copyright to your article

Submit your next manuscript at $\boldsymbol{\nabla}$ springeropen.com 